\title{
A construção identitária nas aulas de educação física
}

\author{
MARCOS VINICIUS PEREIRA MONTEIRO \\ Colégio Pedro II, Rio de Janeiro, RJ, Brasil
}

\section{RESUMO}

Este artigo discute a construção identitária e sua relação com as aulas de educação física valendo-se de significados construídos por estudantes. Influenciadas pela sociedade, as construções identitárias dos diferentes sexos são bastante díspares quanto às suas relações com as atividades físicas. Para buscar um melhor entendimento sobre o tema, são analisados o masculino e o feminino como criações culturais, às relações de gênero e poder e o processo de criação de corpos dóceis. $\mathrm{O}$ estudo foi realizado em uma escola estadual em Nova Iguaçu/RJ, e os dados foram obtidos por meio da realização de entrevistas com alunos/as do $3^{\circ}$ ano do ensino médio. Após a utilização da técnica de análise de conteúdo, os resultados demonstraram que ao final do ensino médio, na escola estudada, a educação física auxilia na construção identitária dos/as alunos/as que representam o masculino como superior, naturalizando a sua maior participação e desempenho nas aulas da disciplina.

\section{PALAVRAS-CHAVE}

construção identitária; educação física; gênero; escola; atividade física. 


\title{
THE IDENTITY CONSTRUCTION IN PHYSICAL EDUCATION CLASSES
}

\begin{abstract}
This article discusses construction of identity and its relationship to physical education classes, from meanings constructed by students. Influenced by society, identity constructions of different sexes are quite disparate as their relationships with physical activities. To get a better understanding on subject, is considered masculine and feminine as cultural creations; gender relations and power and creation of docile bodies process. The study was conducted in a public school in Nova Iguaçu/RJ, and data were obtained through interviews with ten students of the third year of high school. After the use of the content analysis technique, the results show that the end of high school at the school, physical education acts assisting construction of an identity students those representing male as superior, naturalizing their greater participation and performance in class discipline.
\end{abstract}

KEYWORDS

identity construction; physical education; gender; school; physical activity.

\section{LA CONSTRUCCIÓN IDENTITÁRIA EN LAS AULAS DE EDUCACIÓN FÍSICA}

\section{RESUMEN}

Este artículo analiza la construcción identitária y su relación con las aulas de educación física, desde los significados construidos por los alumnos. Influenciado por la sociedad, las construcciones identitárias de diferentes sexos son bastante dispares como sus relaciones con las actividades físicas. Para tener una mejor comprensión sobre el tema, se analiza el masculino y lo femenino como creaciones culturales; las relaciones de género y poder y el proceso de creación de cuerpos dóciles. El estudio se realizó en una escuela estatal en Nova Iguaçu/RJ, y los datos se obtuvieron a través de entrevistas com diez alumnos del tercer año de la escuela secundaria. Después de la utilización de la técnica de análisis de contenido, los resultados muestran que en la escuela la educación física actúa ayudando a la construcción identitária de los/las alunos/as que representan a los hombres como superior, naturalizando su mayor participación y rendimiento en la disciplina.

PALABRAS CLAVE

construcción identitária; educación física; género; escuela; actividade física. 
O conceito de gênero "explicita o ser mulher e o ser homem como uma construção histórico-social [...], diferenciando-se, assim, do restrito conceito biológico de sexo, que tende a explicações das diferenças entre feminino e masculino como fruto da natureza" (Gonçalves Junior; Ramos, 2005, p. 5). Desta feita, entende-se que as relações de construção de gênero estão em constante mudança e que os relacionamentos sociais têm grande importância nisso. O gênero não é apenas reproduzido socialmente, mas também construído e transmitido de uma geração a outra. Prova disso em nosso país é a forte divisão de gênero entre as expectativas para brincadeiras e gostos. É muito comum observar pais dizendo às filhas para não praticarem determinados esportes, principalmente aqueles que envolvem maior contato físico; em contrapartida, muitas vezes, causa risos dizer que um menino dança com leveza.

Essas construções sociais constantemente adentram a escola e impactam as aulas de educação física, dificultando a prática coeducativa, ou seja, as aulas em que meninos e meninas realizam atividades juntos e que o respeito pelas diferenças é discutido e vivenciado (Darido, 2003). É curioso verificar, principalmente por parte dos meninos, a constante reclamação sobre as atividades coeducativas das aulas, quando propõem que as meninas "joguem depois" ou então fiquem brincando em outros espaços (normalmente menores e/ou com importância inferior). Por parte das meninas também é frequentemente observado a reclamação de que os meninos poderiam impedi-las de participar nas aulas. Tais situações ocorrem principalmente quando o tema abordado trata de diversos esportes, quando os meninos acabam por considerar que as meninas não possuem a habilidade esportiva necessária ou simplesmente as excluem por serem mulheres. Outras vezes, são as meninas que se recusam a participar com os meninos por considerá-los demasiadamente violentos e sem educação. Existem ainda momentos em que as atividades coeducativas conseguem ser implementadas pelos docentes com sucesso.

Quanto à construção identitária, Hall (2006) alerta sobre a ocorrência de uma mudança estrutural nas sociedades modernas que fragmenta as paisagens culturais de classe, gênero, sexualidade, etnia, raça e nacionalidade, as quais antigamente nos forneciam sólidas localizações como indivíduos sociais. Isso acaba por mudar nossas identidades pessoais, abalando a ideia que temos de nós, com o sujeito tornando-se fragmentado, composto de várias identidades, às vezes até mesmo contraditórias ou não resolvidas.

Tendo tais questões em vista, este artigo apresenta um recorte de pesquisa mais ampla, de mestrado, realizada em uma escola pública estadual localizada na cidade de Nova Iguaçu, região metropolitana do estado do Rio de Janeiro, com alunos/as do $3^{\circ}$ ano do ensino médio, que enfocou os significados construídos por eles/as acerca de questões de gênero e sua inter-relação com as aulas de educação física, assim como sobre as atitudes e práticas docentes.

Este artigo focaliza um aspecto que se evidenciou de forma enfática na mencionada pesquisa: a construção identitária dos alunos e sua relação com a aula de educação física e as atividades físicas em geral.

O motivo de escolher os alunos/as que estão no ano de encerramento da educação básica permitiu levantar hipóteses sobre até que ponto a educação física 
atingiu nesse grupo os objetivos escolares preconizados pelos Parâmetros Curriculares Nacionais quando dizem: "participar de atividades corporais [...] sem discriminar por características pessoais, físicas, sexuais ou sociais" (Brasil, 1997, p. 43), e também pelas orientações curriculares para o ensino médio "desmitificar o discurso acerca da virilidade masculina e da fragilidade feminina quanto às capacidades e habilidades físicas, proporcionando aos grupos vivências corporais e debates sobre valores morais e étnicos de cunho sexista" (Brasil, 2006, p. 236).

É importante salientar que, desde seu início no ambiente escolar, a educação física enfrentou problemas com as alunas e seus responsáveis, que não consideravam tal atividade adequada às mulheres. Rosemberg $(1995$, p. 279) cita um relatório do diretor da instituição pública do Rio de Janeiro datada de 1874 sobre a tentativa da introdução da ginástica nas escolas femininas. Diz o relatório:

Repugnância com que foi recebida pela opinião pública a aula de ginástica [...]. Foi preciso suspender a execução e ainda assim houve pais que proibiam às suas filhas o exercício ginástico [...] chegou a tal ponto a oposição que algumas alunas [...] deixavam de ir acinte à de ginástica, ficando todavia no edifício da escola.

Até os dias de hoje, as construções identitárias dos diferentes sexos são bastante díspares quanto às suas relações com as atividades físicas, e é isso que veremos neste artigo, que vem dar voz aos alunos/as para que assim expressem a sua construção identitária e os significados por eles/as construídos sobre as diversas atividades físicas. Assim, é analisado o masculino e o feminino enquanto criações culturais; as relações de gênero e poder e a criação de corpos dóceis, para em seguida apresentar a metodologia do estudo, a análise dos dados e as considerações finais.

\section{O MASCULINO E O FEMININO ENQUANTO CRIAÇÕES CULTURAIS}

Tudo o que o ser humano faz está inserido em um contexto cultural. $\mathrm{O}$ conceito de cultura utilizado neste trabalho é entendido como o produto da sociedade à qual os indivíduos pertencem, antecedendo-os e transcendendo-os (Brasil, 1997). Desde o seu nascimento, o ser humano é impactado pela cultura, que deixa suas marcas por meio de, muitas vezes, limitações e controles, de acordo com o momento histórico. Isso pode ser comprovado pelas diferentes formas de expressão corporal dos variados povos: o ser humano é ao mesmo tempo produtor e produto da cultura.

O corpo generificado se molda por meio do estímulo ou punição aos comportamentos apresentados por cada um dos sexos, e sempre representará também a sua cultura. Não se deve esquecer também que as condutas aprendidas individualmente podem sofrer alterações pela forma como cada indivíduo se apropria dessas influências. Em muitas sociedades, inclusive na nossa, tal construção gera expectativas de comportamentos diferentes para cada um dos sexos. As mulheres, durante grande parte da história, tiveram seus direitos limitados em diferentes locais e períodos, além de terem sua participação social relegada muitas vezes à esfera familiar. Enquanto 
aos homens cabia o mundo do trabalho, o poder e as decisões sobre os rumos da sociedade por intermédio dos governos e das Forças Armadas.

Podemos, então, buscar compreender aquelas definições culturais sobre como se devem portar em determinadas situações o "masculino" e o "feminino", pois "as mulheres aprendem a ser femininas e submissas e são controladas nisto, mas também os homens são vigiados na manutenção de sua masculinidade"(Torrão Filho, 2005, p. 139) - processo social que leva ambos a terem um espaço reduzido de afastamento do considerado adequado.

Porém é importante salientar que há espaços para a transformação cultural, não sendo possível fixar com precisão um momento em que a construção cultural do corpo ocorre ou finaliza, pois sua produção e transformação são constantes. Deve-se considerar também que, se essa construção e hierarquização podem ser ensinadas e reproduzidas, não há dúvida de que elas podem ser mudadas, pois os sujeitos se constroem como masculinos ou femininos ininterruptamente. Entretanto, a mudança não ocorre de maneira simples, pois nesse ambiente cultural os indivíduos que não cumpram as funções sociais destinadas para cada sexo em diferentes contextos acabam muitas vezes sendo vítimas de um preconceito.

Para DaMatta (1987 apud Daólio 2005, p. 39), “[...] existem tantos corpos quanto há sociedades". A recíproca também é verdadeira e, quando atuamos nos corpos, modificamos também as sociedades por meio do processo de socialização, que é justamente onde são aprendidos comportamentos e crenças valorizados pelo grupo cultural (família, escola, amigos e outros) do qual o indivíduo faz parte.

Como essa construção cultural do corpo é algo transmitido pelas pessoas, um conceito muito importante, passa a ser o de estereótipos, que, segundo Fleuri (2006, p. 498), "indica um modelo rígido a partir do qual se interpreta o comportamento de um sujeito social, sem se considerar seu contexto e a sua intencionalidade. $\mathrm{O}$ estereótipo representa uma imagem mental simplificadora de determinadas categorias sociais". Estudo de Romero (1990) com quatrocentos e sete professores evidencia o reforço de comportamentos estereotipados entre docentes de educação física de acordo com o senso comum do restante da sociedade; "[...] o próprio professor, independente do seu sexo, tem atuação direta no reforço de padrões de papel sexual [...]"(idem,p.252). Este estudo corrobora o de Thompson (1981 apud Oliveira 1996), que relata a diferença observada no tratamento dos professores relativo aos meninos e às meninas, mas que estes apresentam falta de consciência sobre tal fato. Assim, os fatores sociais acabam determinando as expectativas que as pessoas possuem umas com relação às outras. Influenciando até mesmo na prática pedagógica e na aprendizagem quando a escola passa a achar normais os estereótipos, sem fazer a devida contestação.

Por meio da inculcação de valores forma-se uma limitação das potencialidades discentes, pois alunos e alunas incorporam aprendizados em um processo de condicionamento sobre aquilo que se deve preferir e/ou desejar, assim como aquilo que se deve rejeitar. Isso faz com que os mais diversos tipos de habilidades sejam desenvolvidos ou não de acordo com cada sexo. Muitos desses aprendizados estereotipados ocorrem na escola por meio daquilo que é denominado currículo oculto, "constituído por todos aqueles aspectos do ambiente escolar que, sem fazer 
parte do currículo oficial, explícito, contribuem de forma implícita, para aprendizagens sociais relevantes" (Silva, 2011, p. 78). Portanto, essas relações ocorrem entre todos/as aqueles/as presentes no ambiente escolar, principalmente guiadas pelos/as que detêm o poder e podem assim determinar as normas e regras de comportamento. Essa intencionalidade é comprovada, pois "os processos de escolarização sempre estiveram - e ainda estão - preocupados em vigiar, controlar, modelar, corrigir, construir os corpos de meninos e meninas, de jovens homens e mulheres" (Louro, 2000 apud Santos, 2009 p. 221).

Quanto às aulas de educação física, os/as professores/as podem, por exemplo, proteger as meninas afastando-as dos meninos, por considerarem essa convivência perigosa para elas em virtude da percepção de que eles são "fortes e violentos". Não devemos esquecer que os/as professores/as também têm uma vida pregressa na qual vivenciaram as relações de gênero em casa, escolas, graduações, enfim, em todos os ambientes culturais em que conviveram ou convivem; assim, muitas vezes não têm a condição de perceber os estereótipos que estão reproduzindo.

Não se deve ignorar o fato de que as naturalizações também ocorrem entre os/as alunos. Para Serbin (1984 apud Altmann 1998, p. 40), "a presença de algum par, principalmente do outro sexo, é suficiente para a criança se conformar com seu estereotipo sexual, fazendo atividades adequadas a ele". Até que ponto isso seria natural? Ou seria na verdade um longo aprendizado que coloca cada um cumprindo o papel socialmente designado para o seu gênero? Uma descoberta interessante feita por Oliveira (1996), no contexto da educação física, é que meninas e meninos afirmam brincar com ambos os sexos fora da escola, enquanto dentro dela eles diziam se relacionar mais proximamente somente com pessoas do mesmo sexo. A autora conclui: "acredita-se que do lado de fora da escola, em algumas situações, chega a haver menos preconceito do que no seu interior" (idem, p. 90). Qual motivo levaria as crianças a essa mudança comportamental?

A família também tem grande importância no processo de construção e/ou reconstrução identitária. Muitas vezes é ela quem começa a construir os estereótipos, incluindo aqueles referentes a brinquedos e jogos, pois são pais e familiares quem primeiro disponibilizam brinquedos e ensinam as primeiras brincadeiras de acordo com suas crenças. Isso evidencia a transmissão do patrimônio lúdico por intermédio das gerações e mostra até mesmo um cerceamento inicial no leque de escolhas disponíveis, que pode parecer muito ampla, mas que na verdade é bem limitada. Como disse Grando (2009, p. 33): “o processo de educação do corpo se dá de maneira informal e continuamente ao longo da vida, mas é mais evidente no período da infância". Nesse sentido, meninos são incentivados a participar de brincadeiras mais livres e agressivas, enquanto meninas participam de brincadeiras em locais menores e com pouca movimentação ou risco. Independentemente da classe social, os brinquedos estão distantes de serem destituídos de significado.

Quem bem exemplificou essa situação sobre a influência cultural foi Daólio (2006, p. 76), referindo-se à ocasião do nascimento dos meninos:

Na porta do quarto da maternidade, os pais penduram uma chuteirinha e uma camisa da equipe de futebol para a qual torcem. Pouco tempo depois, dão-lhe 
uma bola e o estimulam aos primeiros chutes. Um pouco mais tarde, este menino começa a brincar na rua - futebol, pipa, subir em árvores, carrinhos de rolimã, skate, bolinha de gude, bicicleta, taco etc. - porque, segundo as mães, se ficar em casa vai atrapalhar.

Quanto às meninas, ainda Daólio (idem, p. 77) diz que elas são criadas sob uma névoa de delicadeza e cuidados:

as meninas ganham de presente, em vez da bola, bonecas e utensílios de casa em miniatura. Além disso, são estimuladas o tempo todo a agir com delicadeza e bons modos, a não se sujarem, não suarem. Portanto, devem ficar em casa a fim de serem preservadas das brincadeiras de menino e ajudarem as mães nos trabalhos domésticos, que lhes serão úteis futuramente, quando se tornarem esposas e mães.

Outros autores corroboram com esse pensamento: "dar a meninas e meninos brinquedos diferentes poderia ser inofensivo, exceto pelo fato de que brinquedos criam aspirações, afiam aptidões conceituais e estimulam certos comportamentos em detrimento de outros" (Schienbinger, 2001 apud Bitencourt, 2010 p. 184). Romero (1990) aponta que em uma festa de aniversário é possível identificar o sexo da criança somente pelos presentes recebidos.

Infelizmente, essa não é uma realidade distante. O produto Kinder Ovo, da marca Ferrero, que é vendido no Brasil desde 1994, no ano de 2013 começou a separar seus produtos por sexo, lançando as versões "meninos" e "meninas"; antes disso, qualquer criança podia receber o brinquedo que vinha dentro do produto, indistintamente. Numa análise da embalagem desse produto, percebe-se a existência de vários estereótipos: a versão para meninos possui a cor predominante azul e brinquedos como carrinhos e monstros, já na embalagem para meninas a cor predominante é rosa, possuindo bonecas e animais domésticos como brinquedos. Existem alguns poucos produtos (ligados a personagens de desenhos animados) que estão disponíveis para os dois sexos, porém as embalagens também são na cor azul e rosa.

Souza (2010, p. 259), em pesquisa sobre as masculinidades, evidenciou a diferença no tratamento dos filhos conforme o sexo. Nessa pesquisa, o autor colheu depoimento de um pai com dois filhos (uma menina de 15 anos e um menino de 10) que dizia dar pouca liberdade para a filha, enquanto o menino, apesar de ser mais novo, podia ficar mais tempo na rua "porque ele é homem", comprovando o processo de enclausuramento das mulheres com o propósito de proteção. Estudo de Santos e Dias (2010), com crianças que brincavam na rua no nordeste brasileiro no estado de Sergipe, corrobora essa ideia, pois, das 32 crianças observadas, 69\% eram meninos e apenas $31 \%$, meninas.

Cria-se assim um círculo vicioso em que meninas brincam e desenvolvem atividades relacionadas à motricidade fina e gestos delicados, e não desenvolvem o aspecto motor amplo e o melhor desempenho em atividades expansivas, ao contrário do que ocorre com os meninos. Isso acaba por afastar as meninas das brincadeiras 
com os meninos e do desenvolvimento de suas potencialidades, pois concluem que não nasceram para praticar atividades físicas. Outro aspecto que pode influenciar na escolha das atividades esportivas é a relação com o comportamento dos pais filhos de pais e/ou mães que praticam atividades físicas ou frequentam locais de prática podem ser influenciados por essa vivência e terem maiores possibilidades de se sentir pertencentes a esse ambiente.

Com esse panorama, as crianças que vão contra as expectativas sociais são vistas muitas vezes com preconceito, sendo alvo de tratamentos jocosos. Assim, as meninas agitadas são criticadas pelos maus modos, sendo consideradas frequentemente masculinizadas, enquanto meninos com o mesmo comportamento são considerados normais e sadios. Esse fato pode também ser notado quando professores/as esperam comportamentos mais agitados dos meninos e se surpreendem quando são as meninas as mais agitadas e as rotulam dizendo: "parece um menino", "comporte-se como uma mocinha". Como se o fato de uma menina ser agitada fosse diagnóstico de um distúrbio qualquer. Devemos considerar as diferenças entre os alunos como enriquecedoras das vivências, e não apenas problemas para o bom andamento das aulas. Tal diferença serve também para gerar debates em aula com o objetivo de aumentar o respeito mútuo e proporcionar oportunidades iguais a todos. As desigualdades só poderão ser percebidas e desestabilizadas à medida que estivermos atentos para suas maneiras de produção e reprodução.

Nesse ponto, percebe-se que a disciplina educação física produz corpos e por isso também é necessária uma reflexão crítica sobre o modo como essa construção ocorre, assim como a ligação desta com as relações de gênero e o poder.

\section{GÊNERO E PODER}

As relações de gênero estão intrinsecamente ligadas às relações de poder, pois no interior delas são instituídas as desigualdades; assim, é de muita valia se pensar o modo como as relações de gênero constroem e articulam o poder na sociedade. As estruturas de dominação historicamente se reproduzem de maneira que "os dominados aplicam categorias construídas do ponto de vista dos dominantes às relações de dominação, fazendo-as assim ser vistas como naturais. O que pode levar a uma espécie de autodepreciação ou até de autodesprezo sistemáticos”, segundo Bourdieu (2011, p. 46).

Tal estrutura gera uma violência simbólica sobre os indivíduos, assim denominada por não ser uma violência física, em que os corpos seriam agredidos fisicamente, e sim uma violência presente no campo das ideias e da repressão, na qual os corpos são atingidos psicologicamente, com censuras e punições a determinadas formas de comportamento. Dessa maneira, os dominados muitas vezes expressam emoções tais como vergonha, timidez, ansiedade, culpa, raiva, gaguejar, enrubescer quando sentem estar rompendo a linha imaginária entre aquilo que deve ser feito por dominados e aquilo que deve ser feito por dominantes. Isso quando não se punem por fazer coisas contra a própria vontade, pois optam por realizar aquilo que é socialmente desejado. Assim, mulheres e homens indistintamente são vítimas 
dessa repressão dominante que atinge seus direitos, incluindo o direito de fazer o que quiser com seu próprio corpo.

Ninguém é "por natureza" dominante ou submisso/a, mas há momentos de submissão e resistência. Todos são alvo de construções culturais que diferenciam os gêneros que devem assim cumprir determinadas representações; quando tais características são absorvidas, muitas pessoas as chamam pelo nome de vocação, na qual "as vítimas da dominação simbólica possam cumprir com felicidade (no duplo sentido do termo) as tarefas subordinadas ou subalternas que lhe são atribuídas [...]" (idem, p. 73). Dessa maneira, os dominados tornam-se submissos a determinados atos que acabam por ser uma demonstração simbólica do modo de ver o mundo que representa a ideologia dominante. Dessa maneira, os dominados participam de sua própria dominação. Esse poder imposto atua gerando corpos dóceis e diminuindo a força política dos sujeitos: antes de buscar o prazer, um indivíduo acaba muitas vezes por pensar como esse ato seria visto pela sociedade, desta feita o poder acaba por disciplinar os corpos. Somente poderemos transformar essa situação quando conseguirmos romper essa reprodução cultural de dominação e subordinação.

Por meio de questionamentos e reflexões, nas últimas décadas ocorreram alterações nas relações entre os sexos e a diminuição das diferenças entre eles. Porém ainda é necessário que mais mulheres alcancem postos de poder, que a remuneração no trabalho seja mais igualitária e que haja equilíbrio entre as atividades domésticas de cuidados com a família e outras ações que possibilitem a igualdade.

Sobre a incorporação do processo de dominação, Bourdieu (idem, p. 114) reflete de maneira apropriada quando diz:

Em suma, através da experiência de uma ordem social sexualmente ordenada e das chamadas à ordem explícitas que lhes são dirigidas por seus pais, seus professores e seus colegas e dotadas de princípios de visão que elas próprias adquiriram em experiências de mundo semelhantes, as meninas incorporam, sob formas de esquemas de percepção e de avaliação dificilmente acessíveis à consciência, os princípios da visão dominante que as levam a achar normal, ou até mesmo natural, a ordem social tal como é e a prever, de certo modo, o próprio destino, recusando as posições ou as carreiras de que estão sistematicamente excluídas e encaminhando-se para as que lhes são sistematicamente destinadas.

\section{A FABRICAÇÃO DOS CORPOS DÓCEIS E SUA IMPORTÂNCIA ENQUANTO INSTRUMENTO DE PODER}

O processo de tornar os corpos dóceis é muito importante para que seja viável o exercício de um poder que diminua a necessidade de ocorrer sanções sobre esse corpo que é alvo constante do poder. Em seu livro Vigiar e punir, Foucault (2011) diz que o corpo dócil é aquele que pode ser submetido, utilizado, transferido e aperfeiçoado, tornado útil e possível de controle, podendo assim se ter domínio sobre ele, para que faça o que se quer. 
O corpo disciplinado realiza gestos eficientes e adequados, além de tornar os sujeitos objetos e instrumentos do exercício de poder. O "poder disciplinar" se exerce por meio de sua invisibilidade em que a constante vigilância dos olhares acaba colocando os indivíduos visíveis, pois sempre se tornam o centro das atenções. $\mathrm{O}$ mais importante para a manutenção desse poder é o fato de os indivíduos saberem que estão sujeitos a isso e dessa maneira limitarem suas ações àquilo aceito socialmente.

Os indivíduos que não se comportam de acordo com o esperado são alvo de punições sociais com a intenção de se reduzir desvios. Essas punições frequentemente não são visíveis com os punidos sendo relegados a um isolamento social, pois as pessoas preferem não se relacionar com aqueles que não possuem uma conduta que julgam adequada. A lógica é que esse tipo de sanção faça o indivíduo agir conforme os papéis que se espera. Assim, muitas vezes, na tentativa de evitar punições futuras e talvez até receber reforços positivos, o indivíduo passa a agir conforme o esperado socialmente.

Talvez essa sanção pelo olhar seja a causa de poucas mulheres formarem grupos para a prática de esportes em quadras públicas, utilizando tais espaços mais para práticas relacionadas à beleza e a obtenção de saúde, como caminhadas e diferentes tipos de ginásticas. Um dado que confirma essa afirmação está presente no estudo de Kruchelski, Grande e Wendling (2011), que avaliaram as características de utilização das academias ao ar livre na cidade de Curitiba/PR, que são estruturas públicas construídas com o objetivo de melhorar o nível de atividade física da população. Entre aqueles/as que utilizavam tal estrutura, 64\% eram mulheres. Esse dado torna-se relevante quando comparado aos dados do Censo 2010 (IBGE, 2012), que indicou que $52 \%$ da população desse município era composta de mulheres. Em contrapartida, a mulher que pratica esporte não é vista como fisicamente atraente em virtude do desenvolvimento muscular ou tem sua sexualidade questionada. Melo, Giavoni e Tróccoli (2004) estudaram e confirmaram que biótipos de mulheres que praticam esportes desencadeavam estereótipos sexuais por parte de grupos que não apresentavam envolvimento desportivo. O estudo confirmou ainda a presença desses estereótipos com as atletas sendo consideradas menos atraentes.

\section{METODOLOGIA}

No presente estudo foi utilizada uma abordagem de cunho qualitativo. Em se tratando de uma pesquisa qualitativa, não se teve a intenção de chegar a generalizações, mas sim lançar hipóteses e questionamentos que deverão ser investigados e aprofundados por futuros estudos, visto que o objetivo da análise qualitativa é, segundo Bogdan e Biklen (1994), melhor compreender o comportamento e a experiência humanos e o processo mediante o qual as pessoas constroem significados, descrevendo em que consistem tais significados. A coleta de dados foi realizada por 
meio de entrevistas semiestruturadas com os sujeitos selecionados. Todos possuindo 18 anos e tendo assinado o Termo de Consentimento Livre e Esclarecido. ${ }^{1}$

Foram realizadas dez entrevistas com alunos/as do sexo feminino e masculino, de diferentes turmas do $3^{\circ}$ ano do ensino médio. Contamos com a indicação dos próprios alunos para chegar aos informantes fazendo uso da técnica chamada snowball,"pela qual cada novo informante indica novas pessoas para participarem da pesquisa" (Víctora; Knauth; Hassen, 2000, p. 38). Foi feita uma inclusão progressiva dos sujeitos, interrompida pelo critério de saturação, ou seja, quando as respostas passaram a ter uma regularidade de apresentação.

Os sujeitos deveriam se inserir em quatro grupos diferentes, de acordo com o sexo e a participação nas aulas de educação física:

Grupo A: alunas que sempre participam da parte prática das aulas de educação física;

Grupo B: alunas que nunca ou quase nunca participam da parte prática das aulas de educação física;

Grupo C: alunos que sempre participam da parte prática das aulas de educação física;

Grupo D: alunos que nunca ou quase nunca participam da parte prática das aulas de educação física.

Os informantes foram identificados pelos seguintes códigos: primeira letra referente ao sexo ( $\mathrm{H}$ - para homens ou $\mathrm{M}$ - para mulheres); em sequência é definida sua participação ou não nas aulas (PART - para alunos/as que participam ou SEMPART - para alunos/as que não participam), em seguida, foram usados algarismos arábicos, de acordo com a quantidade de sujeitos pertencentes ao grupo (os algarismos adotados foram 1, 2 e 3). Assim, tivemos:

\section{Grupo A: MPART1, MPART2 e MPART3; \\ Grupo B: MSEMPART1, MSEMPART2 e MSEMPART3; \\ Grupo C: HPART1 e HPART2; \\ Grupo D: HSEMPART1 e HSEMPART2.}

As entrevistas foram realizadas no ano de 2013, na unidade escolar escolhida para o estudo, em um local onde se encontravam apenas o entrevistador e o entrevistado/a, assegurando assim condições para que o/a último/a se sentisse confortável na emissão de suas respostas.

Para a análise dos resultados, foi utilizada a análise de conteúdo. Após as entrevistas e sua transcrição, foi feita a leitura compreensiva do material buscando ter uma visão do todo e apreender suas particularidades. Em seguida, foi realizada

1 Com o número CAAE 09062512.5.0000.5286, o estudo foi cadastrado na Plataforma Brasil e encaminhado para o Comitê de Ética do Instituto de Estudos em Saúde Coletiva da Universidade Federal do Rio de Janeiro (IESC/UFRJ). 
a exploração do conteúdo, no qual, segundo Gomes (2011, p. 101), é importante "sermos capazes de ir além das falas e dos fatos ou, em outras palavras, caminharmos na direção do que está explícito para o que é implícito, do revelado para o velado, do texto para o subtexto". Para auxiliar no cumprimento dessa etapa, foi construído um quadro com a sistematização dos dados, em que extratos dos depoimentos dos/as alunos/as foram relacionados a seus respectivos significados. Após, foi elaborada a síntese interpretativa das falas dos sujeitos, fazendo a articulação entre os objetivos do estudo, os dados colhidos, a teoria e a revisão de literatura. Nesse processo, optou-se por não corrigir os eventuais erros gramaticais na fala dos/as entrevistados/as.

As categorias identificadas nos dados colhidos e que constam da análise foram:

a) A naturalização do masculino como superior na disciplina;

b) A dicotomia corpo/mente e o desempenho nas demais disciplinas;

c) Os motivos para uma baixa participação feminina nas aulas;

d) Mulheres como pessoas naturalmente frágeis.

\section{ANÁLISE DOS DADOS}

Pôde-se perceber que os/as alunos/as em vários momentos das entrevistas realizaram afirmações que naturalizavam aspectos relativos ao desempenho durante as aulas e aos gostos individuais dos/as alunos/as. Tais falas frequentemente se baseavam em conceitos biológicos e deterministas, não levando em consideração os aspectos culturais das relações sociais.

Alguns/mas entrevistados/as demonstravam considerar "natural" o melhor desempenho durante as atividades físicas dos alunos e também a falta de interesse das alunas, pelos mais diversos motivos. Isso acaba por gerar um desequilíbrio nas relações de poder existentes durante a aula, pois qualquer predomínio masculino é visto como "normal", enquanto para as alunas sobra amiúde o papel de coadjuvante durante a aula. Essa situação acaba influenciando nas percepções que os alunos têm do que ocorre na aula, causando assim impactos em suas construções identitárias.

Com relação a uma suposta maior capacidade desportiva masculina nas atividades físicas e em particular nas aulas de educação física, conduzindo a uma construção do masculino como superior, apareceram as seguintes falas:

[...] os meninos são mais fluentes, são mais capazes [...] eles têm mais jeito. (MPART1)

[...] os meninos são sempre melhores [...] [eles] têm mais força. (MPART2)

[...] homem sempre é bom nesse negócio de físico, preparo, basquete, vôlei, sempre o homem é melhor. (MPART2)

[...] as meninas não têm a mesma resistência que os garotos; quer dizer, para competir com os garotos, as meninas não podem e a questão é isso mesmo. (HSEMPART2) 
Além dessas afirmações, a aluna MPART2 afirmou que, caso as aulas fossem separadas por sexo, um dos grupos teria um nível de desempenho mais baixo. Segundo ela, a turma com o nível mais baixo seria a "das meninas, com certeza".

$\mathrm{O}$ aluno HPART2 seguiu no mesmo caminho das afirmações anteriores e disse que, para um homem aprender determinado esporte, basta ele querer, fazendo ainda uma ligação desse fato com a sua percepção de que as mulheres gostavam mesmo era de assistir a novelas na televisão:

[...] mulher não pensa muito em esporte, assim, pensa? [...] fala assim: "esse esporte eu não vou me dar bem" [...], mas homem não: "vou fazer aquele esporte ali, vou tentar", e vai [e] consegue [...]. Você vê muita mulher mais na novela, mas no esporte é muito raro ver.

Segundo Gobbi (1996 apud Leite, 2002, p. 68), "a menina é preparada desde a infância para ser mãe; mesmo que nunca seja, trata-se de um rito de passagem para o qual a mulher é preparada durante grande parte da sua vida”. Essa condição cultural, inclusive, gera dificuldades para se revelar quais as reais possibilidades e limitações de homens e mulheres, pois seria impossível fazer um experimento sem que os indivíduos fossem impactados pelas condições ambientais.

Ao contrário, com relação às demais disciplinas escolares, em algumas falas foram utilizados estereótipos das mulheres como mais calmas e concentradas, enquanto os meninos não aprendem porque simplesmente não levam as aulas a sério.

[...] acho as meninas um pouco mais inteligentes do que os homens.(MPART1)

[...] a menina é mais centrada, é mais calma, são as que se concentram mais. (MPART1)

[...] o desempenho [melhor] nas [outras] disciplinas é mais as meninas na minha turma [...]. (HSEMPART1)

[...] as meninas são mais inteligentes. (MPART2)

[...] na sala de aula os meninos gostam mais é de ficar brincando, aí não presta muito atenção, aí as meninas não, já prestam mais atenção na aula. (MPART3)

Essa clara diferenciação percebida nas falas entre os meninos que praticam esportes e as meninas que são mais inteligentes revela um significado referente à construção identitária de dicotomia corpo/mente; significado que também apareceu na fala do aluno HSEMPART2, que, ao responder à pergunta sobre a capacidade dos/as alunos/as nas demais disciplinas, afirmou: "geralmente é assim, quem sabe jogar só tem interesse em educação física, geralmente não tem uma boa nota, um bom conceito com as outras disciplinas, é uma coisa que eu realmente reparo". Tal afirmação é muito comum em nossa sociedade, sendo também muitas vezes um dos motivos que levam à desvalorização da educação física no ambiente escolar, pois, por meio dessa dicotomia ocorre a separação entre o trabalho e o corpo - processo que é visto como o objetivo da disciplina educação física (de menor valor, tal qual o 
trabalho braçal) e no qual o trabalho intelectual (alvo das demais disciplinas) acaba por ser mais valorizado.

O aluno HSEMPART2, apesar de conceber em sua fala a atividade física como algo masculino, evidenciou não entender muito bem de que maneira isso ocorre na sociedade:

[...] acho que é também por falta de interesse das meninas, eu não entendo a questão delas não querer fazer; simplesmente eu acho que os garotos estão mais ligados ao esporte. [...] talvez porque elas não tenham oportunidade de jogar com outras meninas, né? [...]

Acompanhando esse pensamento, a aluna MPART1 criticou o machismo na sociedade, que acaba por permitir menos experiências físicas para as mulheres:

[...] eu acho que é um pouco mesmo de machismo, é um pouco de preconceito, porque acham que só os homens podem, não há tanto como antigamente, mas é possível perceber o reflexo disso, aqueles que ainda acham que [o esporte é] mais para os homens do que para mulheres. (MPART1)

É interessante notar que, apesar de a aluna MPART1 refletir sobre o machismo da sociedade com relação à prática esportiva, ela foi uma das alunas que consideraram os meninos superiores com relação à disciplina educação física. Podemos relacionar tal posicionamento ao pensamento de Hall (2006), que afirma que na atualidade o processo de identificação torna-se mais provisório, variável e problemático, produzindo o sujeito pós-moderno que não possui uma identidade fixa ou permanente, pois a identidade é transformada continuamente em relação às formas pelas quais somos representados ou interpelados nos sistemas culturais que nos rodeiam, sendo definida assim historicamente, com identidades diferentes assumidas em cada momento, mesmo que de forma não coerente.

Quanto à participação na aula, durante as entrevistas, as alunas afirmaram existir maior participação masculina e buscaram encontrar alguma explicação para isso:

[...] os meninos têm que jogar comigo porque as meninas daqui não gostam muito de jogar. (MPART1)

[...] aqui não tem muita atividade; a maioria dos meninos só joga futebol e as meninas não gosta. (MPART3)

[...] hoje em dia as meninas não querem nada, só quer namorar por telefone [...], ninguém quer mais jogar queimada, handebol, é muito chato. (MSEMPART3)

[...] aqui as meninas são muito desanimadas. (MSEMPART3)

As alunas acabam, durante as aulas, fazendo inúmeras outras atividades, como conversar, ficar na biblioteca, ficar fora da área reservada para a aula, namorar ou 
falar ao telefone, mesmo sendo essa última conduta vedada por lei estadual (Rio de Janeiro, 2009), que proíbe o uso de telefones dentro das unidades escolares. Nota-se que as explicações dadas acabam culpabilizando as meninas por seu baixo índice de participação nas aulas, considerando-as pouco interessadas ou muito vaidosas. Porém, o baixo interesse demonstrado no último ano do ensino médio e relatado por essas alunas relaciona-se na verdade a uma junção de fatos ocorridos durante a vida pregressa dessas discentes, em que seus direitos quanto à prática esportiva são constantemente subtraídos em todas as esferas. Dessa forma, muitas se afastam da atividade física na adolescência, conforme demonstra estudo de Myotin (1995), que examinou os padrões de prática esportiva de 1.497 alunas, com idade entre 11 e 20 anos, em ambientes externos à escola, revelando que o índice de participação feminina em esportes decresce a partir dos 14 anos. Outra descoberta do estudo foi que garotas que praticavam esportes se percebiam menos femininas que as não praticantes.

É perceptível, porém, quanto essas naturalizações dificultam uma mudança na realidade estereotipada existente na sociedade. Hall (2006) afirma que a construção identitária é desenvolvida ao longo do tempo por processos inconscientes, sendo formada constantemente, permanecendo sempre incompleta. Outro processo de naturalização observado foi a percepção dos/as alunos/as de que as mulheres não praticam atividade física porque não gostam de suar.

[...] tem mulher que não gosta de jogar futebol, suar, mulher não gosta de muito contato e muita movimentação, entendeu? Aí também acaba diminuindo, né? [a participação das mulheres nas atividades físicas]. (HPART1)

[...] as meninas não se animam para fazer nada; quando fala sobre queimada: "Ah, a gente vai suar, tem que tomar banho, pentear o cabelo". (MSEMPART3)

Tal discurso não é exclusivo dos/as alunos/as. Em estudo feito por Altmann, Ayoub e Amaral (2011), foi relatada a fala de uma professora que também afirmava que as meninas não gostavam de suar. Outro estereótipo encontrado na fala dos/as entrevistados/as foi de que as mulheres são naturalmente mais frágeis:

[...] se tiver garota, tem que ser mais sensível; e garota é sensível, não adianta falar que garota é mesma coisa que homem, não adianta, [...] se de repente tu não olhar para o lado e esbarrar nela, ela vai cair e vai se machucar, não adianta falar que não se machucou porque a garota é sensível [...]. (HPART2)

A aluna MPART2 também fez referência a essa suposta fragilidade. Ao ser perguntada sobre qual o ponto positivo existente em aulas separadas por sexo, afirmou: "positivo, que menina sabe como é, mais delicada, sem brutalidade".

Com relação a esses construtos sociais da masculinidade e da feminilidade, tradicionalmente os traços individualistas ou instrumentais (independente, agressivo, racional) caracterizam-se como pertinentes à masculinidade, enquanto traços coletivistas ou expressivos (amorosa, sensível, delicada) são pertinentes à feminilidade (Melo; Giavoni; Tróccoli, 2004). Silva, Botelho-Gomes e Goellner (2008 apud 
Knijnik; Falcão-Defino, 2010) dizem que os meninos aprendem que suavidade, fraqueza, vulnerabilidade, timidez, incompetência física e motora são aspectos femininos e devem ser evitados, assim como ser derrotado por elas é um dos piores insultos ao orgulho masculino. É na prática do esporte que o menino demonstra em público "seu desprezo pela dor, o controle do corpo, a força de seus golpes, a vontade de ganhar e esmagar os outros" (Badinter, 1993, p. 94). Porém, nos últimos anos, as mulheres vêm conquistando espaço em esportes que são considerados mais violentos, como o mixed martial arts (MMA) e o boxe olímpico, que passou a incluir a competição feminina a partir dos jogos de 2012 (os homens foram incluídos nos jogos de 1904). Além disso, uma busca simples em qualquer site de vídeos tem como retorno uma quantidade considerável com o descritor "briga alunas", sem uma diferença significante quando o descritor utilizado é "briga alunos".

Entretanto, é importante notar que os estereótipos de uma suposta incompetência motora feminina ainda persistem; alguns/mas alunos/as se referiram à atividade física e/ou prática esportiva por parte das mulheres como algo de menor valor, como evidenciado nos trechos a seguir:

[...] a maioria que vê esses esportes é homem, então nenhum homem quer chegar, ligar sua TV e ver passando futebol de mulher, porque não tem interesse. (HPART2)

[...] não sei se é preconceito, se não tem graça de ver uma mulher correndo atrás de uma bola [...] qual é a graça de ver uma mulher batendo em outra mulher se $[\ldots]$ não vai ser a mesma coisa? [...] muita diferença, assim, de homem para mulher [...]. (HPART2)

[...] eles falam que a gente não sabe jogar. (MPART2)

Também não é de estranhar o fato de o aluno HPART2 utilizar entre suas justificativas para a suposta inferioridade feminina o fato de os esportes femininos terem menor repercussão na mídia:

Eu vejo esporte, assim, de homem [...]. É muito raro ver uma transmissão de basquete feminino ou transmissão de futebol feminino, é mais fácil na ginástica, tem muita mulher na ginástica. Esporte para a mulher é ginástica, flexibilidade. Esporte violento tipo boxe... Tem umas? Tem, muito raro também ver transmissão. Transmissão [de esporte] violento é MMA, que é [praticado por] homem, [...], [passa em] qualquer canal, entendeu?

Com relação ao espaço ocupado pela cobertura dos esportes femininos, pesquisa de Devide et al. (2008), em 44 edições do "Caderno de esportes" do jornal $O$ Globo, relatam que, desconsiderando artigos referentes à modalidade futebol, as matérias que se referiam a atletas homens representavam $71 \%$ do total, enquanto $12 \%$ eram sobre mulheres e $17 \%$, sobre ambos os sexos. Quando se observava as fotos publicadas, essa discrepância diminuía, porém sem grandes alterações. As imagens masculinas representavam $64,5 \%$ do total, as femininas $28,2 \%$ e as imagens 
de ambos os sexos 7,3\%. Nessa mesma pesquisa, quando são incluídas as matérias referentes ao futebol, a situação é a seguinte: $87,5 \%$ das reportagens falavam sobre homens, enquanto somente $4,9 \%$ tratavam a respeito de mulheres. Quanto às imagens, $89,5 \%$ eram de homens e 7,6\% de mulheres.

$\mathrm{Na}$ fala do aluno HPART2, citada anteriormente, também se percebe outro forte estereótipo com relação à generificação das práticas esportivas; alinha-se ao pensamento de muitos de que os diferentes tipos de ginásticas são atividades apropriadas para as mulheres (o que até mesmo leva a um grande preconceito contra os homens que as praticam), haja vista a sua flexibilidade e beleza de movimentos. Esquecem, porém, que tais práticas necessitam também de muitos movimentos que envolvem o uso da força, qualidade física considerada tradicionalmente um atributo masculino. Segundo Simões, Cortez e Conceição (2004, p. 151-152), a discriminação contra o esporte feminino "só se atenua nas modalidades em que as mulheres podem evidenciar sua feminilidade por meio de gestos e dos uniformes desenhados para destacar sua beleza”.

Apesar de todas essas afirmações que denotam uma construção identitária que afasta as mulheres da prática esportiva, a participante MPART2 afirma que as alunas que apresentam habilidade durante as atividades realizadas na aula são aceitas sem problemas pelos meninos.

[...] eles falam que a gente não sabe jogar, só quando a menina é muito "maria chuteira”, aí sim (ela é aceita no jogo dos alunos). Porque ela sabe jogar igualado a eles.

Quanto a esse tema, Abreu (1993) constata na fala dos/as professores/as que inicialmente há um bloqueio dos meninos em aceitar atividades com meninas; porém, quando estas demonstram habilidade, o sexo torna-se irrelevante, ocorrendo, até mesmo por esse motivo, a exclusão de meninos. É também verdade que existe uma predisposição inicial em excluir as meninas por todo um preconceito de que mulher e atividade física não se misturam, e por isso os meninos toleram mais os erros masculinos. Nesse último exemplo, percebe-se que as atividades mistas constituem potencialmente uma forma importante para alterar esse preconceito inicial e histórico, possibilitando uma maior interação entre os gêneros. Essa determinação histórica faz com que muitas vezes em nossa sociedade as meninas sejam alvos de preconceitos e adjetivos pejorativos por serem habilidosas e jogarem com meninos, conforme relatam Altmann (1998) e Pereira (2004 apud Chan-Vianna; Luz Moura; Mourão, 2007). E, como evidencia este estudo, chamar a menina que é habilidosa de "maria chuteira" é também pejorativo.

\section{CONSIDERAÇÕES FINAIS}

Por meio da construção de significados dos/as alunos/as, pôde-se perceber que ao final do ensino médio, na escola estudada, a educação física auxilia em uma construção identitária discente que representa o masculino como superior, naturalizando a sua maior participação e desempenho nas aulas da disciplina. 
Para alterar esse quadro, é importante que os/as professores/as comecem a refletir sobre sua prática pedagógica e a combater os estereótipos que permeiam as aulas, dando à educação física um caráter transformador. É necessário que se auxilie o/a aluno/a a compreender o seu papel na mudança e no questionamento cultural, mostrando que a prática de atividades físicas não é de maneira nenhuma imprópria às mulheres. Caso a disciplina se acomode a uma postura conservadora ou conformadora, estará fabricando corpos submissos aos estereótipos e socialmente acomodados às desigualdades e contradições sociais. Somente por meio do constante questionamento é que se dotará os/as discentes de condições para problematizarem as relações sociais e modificarem seu agir.

Porém, não basta que um/ou outro/a professor/a de educação física se interesse pelo tema e o utilize com frequência em suas aulas. É necessário um esforço de todos os setores envolvidos na prática educativa. É importante que nossas universidades discutam e tornem claro esse tema para seus licenciandos, de modo que eles também valorizem essas ações. Não se pode perder de vista também que a discussão de tal tema é posterior à formação de muitos professores que estão militando em nossas classes; assim, torna-se importante pensar em mecanismos de estímulo para a formação continuada dos/as docentes, para que eles/as possam constantemente ter acesso às discussões mais recentes do campo educacional e também conseguir discutir o tema com seus pares de outras unidades escolares. Caso não ocorram discussões durante a formação profissional, muitos/as professores/as acabarão refletindo sobre a problemática somente quando já em suas escolas (se isso acontecer), e assim talvez jamais se incomodem com essas questões ou então realizem diversas ações de tentativa e erro no intuito de buscar a igualdade de gênero.

Dessa maneira, para que possam usufruir dos seus benefícios, todos, sem exceção, devem ser incluídos nas aulas. Essa igualdade de oportunidades a ser buscada nas aulas de educação física não pode excluir ninguém pelo seu gênero, habilidade ou compleição física. Assim, a disciplina poderá influenciar positivamente na construção identitária de nossos/as alunos/as, repelindo a reprodução dos estereótipos que tentam impor um modelo único de ser masculino ou feminino.

\section{REFERÊNCIAS}

Abreu, N. Meninos pra cá, meninas pra lá? In: Votre, S. (Org.). Ensino e avaliação em educação física. 1. ed. São Paulo: Ibrasa, 1993. p. 101-120.

Altmann, H. Rompendo fronteiras de gênero: marias (e) homens na educação física. 1998. 111f. Dissertação (Mestrado em Educação) - Universidade Federal de Minas Gerais, Belo Horizonte, 1998.

.; Ayoub, E.; Amaral, S. Gênero na prática docente em educação física: "meninas não gostam de suar e meninos são habilidosos ao jogar"? Estudos Feministas, Florianópolis: UFSC; Florianópolis: Copiart, v. 19, n. 2, p. 491-501, maio/ago. 2011.

Badinter,E. XY sobre a identidade masculina. 2. ed. Rio de Janeiro: Nova Fronteira, 1993. 
Bitencourt, S. As relações de gênero na engenharia: diálogos num campo de saber/ poder masculino. In: Souza, M. (Org.). Desigualdades de gênero no Brasil: novas ideias e práticas antigas. 1. ed. Belo Horizonte: Argvmentvm, 2010. p. 171-207.

BogdAN, R.; BLIKEN, S. Investigação qualitativa em educação: uma introdução à teoria e aos métodos. Porto: Porto, 1994.

Bourdieu, P. A dominação masculina. 10. ed. Rio de Janeiro: Bertrand Brasil, 2011.

Brasil. Secretaria de Educação Fundamental. Parâmetros Curriculares Nacionais: $1^{\circ} \mathrm{e}$ $2^{\circ}$ ciclos do ensino fundamental. Brasília: MEC/SEF, 1997.

. Secretaria de Educação Básica. Orientações Curriculares para o Ensino Médio: linguagens códigos e suas tecnologias. Brasília: MEC/SEB, 2006.

Chan-Vianna, A.; Luz Moura, D.; Mourão, L. Gênero e educação física escolar: uma análise das evidências empíricas sobre a discriminação e o sexismo. In: Congresso Brasileiro de Ciências do Esporte, 15., 2007, Recife.Anais... Recife: CBCE, 2007. DAólio, J. Da cultura do corpo. 9. ed. Campinas: Papirus, 2005.

. Cultura, educação física e futebol. 3. ed. Campinas: Editora Unicamp, 2006.

DaMatta, R. O corpo brasileiro. In: Strozenberg, I. (Org.). De corpo e alma. Rio de Janeiro: Comunicação Contemporânea, 1987. p. 76-85.

DARIDo, S. Educação física na escola: questões e reflexões. 1. ed. Rio de Janeiro: Guanabara Koogan, 2003.

Devide, F.; Lima, F.; Batista, R.; Rodrigues, F. Produção de sentidos sobre a visibilidade de mulheres atletas no jornalismo esportivo: interpretações a partir do Caderno de Esporte do jornal "O Globo". In: Romero, E.; Pereira, E.(Orgs.). Universo do corpo: masculinidades e feminilidades. 1. ed. Rio de Janeiro: Shape, 2008.p. 401-416. FLEURI, R. Políticas da diferença: para além dos estereótipos na prática educacional. Educação E̊ Sociedade, Campinas: CEDES, v. 27, n. 95, p. 495-520, maio/ago. 2006.

Foucault, M. Vigiar e punir: nascimento da prisão. 39. ed. Petrópolis: Vozes, 2011.

Gовві, M. Lápis vermelho é de mulherzinha: desenho infantil, relações de gênero e educação infantil. 1996. 145f. Dissertação (Mestrado em Educação) - Universidade Estadual de Campinas, Campinas, 1996.

Gomes, S. Análise e interpretação de dados de pesquisa qualitativa. In: Minayo, M. C. S. (Org.). Pesquisa social: teoria, método e criatividade. 30. ed. Petrópolis: Vozes, 2011. p. 79-108.

Gonçalves Junior, L.; Ramos, G. A educação física escolar e a questão do gênero no Brasil e em Portugal. 1. ed. São Carlos: EdUFSCar, 2005.

Grando, B. Corpo, educação e cultura: as práticas corporais e a constituição da identidade. In: (Org.). Corpo, educação e cultura: práticas sociais e maneiras de ser. 1. ed. Ijuí: Editora Unijuí, 2009. p. 19-51.

Hall, S. A identidade cultural na pós-modernidade. 11. ed. Rio de Janeiro: DP\&A, 2006. iBGE - Instituto Brasileiro de Geografia e Estatística. Censo demográfico 2010. Resultados gerais da amostra. Rio de Janeiro: Ministério do Planejamento, Orçamento e Gestão, 2012. 
Knijnik, J.; Falcão-Defino, P. Esporte e masculinidades: uma longa história de amor, ou melhor, de amizade. In: KNijniK, J. (Org.). Gênero e esporte: masculinidades e feminilidades. 1. ed. Rio de Janeiro: Apicuri, 2010. p. 161-183.

Kruchelski, S.; Grande, D.; Wendling, N. Utilização do ambiente construído: academias ao ar livre em Curitiba. Revista Gestão Pública em Curitiba, Curitiba: ImaP, v. 2, n. II, p. 67-80, maio/ago. 2011.

Leite, M. Brincadeiras de menina na escola e na rua: reflexões da pesquisa no campo. Cadernos CEDES, Campinas: CEDES, n. 56, p. 63-80, abr. 2002.

Louro, G. Corpo, escola e identidade. Educação \& Realidade, Porto Alegre: Universidade Federal do Rio Grande do Sul, v. 25, n. 2, p. 59-75, jul./dez. 2000.

Melo, G.; Giavoni, A.; Tróccoli, B. Estereótipos de gênero aplicados a mulheres atletas. Psicologia: teoria e pesquisa, Brasília: Instituto de Psicologia da Universidade de Brasília, v. 20, n. 3, p. 251-256, set./dez. 2004.

Mrotın, E. A participação da adolescente brasileira em esportes e atividades físicas como forma de lazer: fatores psicológicos e socioculturais. In: Romero, E. (Org.). Corpo, mulher e sociedade. 1. ed. Campinas: Papirus, 1995. p. 177-197.

Oliveira, G. Aulas de educą̧ão física para turmas mistas ou separadas por sexo? Uma análise comparativa de aspectos motores e sociais. 1996. 148f. Dissertação (Mestrado em Educação Física) - Universidade Estadual de Campinas, Campinas, 1996.

Pereira, S. O sexismo nas aulas de educação física: uma análise dos desenhos infantis e dos estereótipos de gênero nos jogos e brincadeiras. 2004. 171f. Tese (Doutorado em Educação Física) - Universidade Gama Filho, Rio de Janeiro.

Rio de Janeiro. Lei n. 5.453, de 26 de maio de 2009, modifica a lei n. 5.222, de 11 de abril de 2008, que dispõe sobre a proibição do uso de telefone celular nas escolas estaduais do estado do Rio de Janeiro. Diário Oficial do Estado do Rio de Janeiro, Rio de Janeiro, 27 maio 2009, parte I, p. 1.

Romero, E. Estereótipos masculinos e femininos em professores de educação física. 1990. 325f. Tese (Doutorado em Psicologia) - Universidade de São Paulo, São Paulo, 1990.

Rosemberg, F. A educação física, os esportes e as mulheres: balanço da bibliografia brasileira. In: Romero, E. (Org.). Corpo, mulher e sociedade. 1. ed. Campinas: Papirus, 1995. p. 271-308.

SAntos, L. Uma experiência de prática curricular acerca das diferenças de gênero e sexualidade. In: Grando, B. (Org.). Corpo, educação e cultura: práticas sociais e maneiras de ser. 1. ed. Ijuí: Editora Unijuí, 2009. p. 207-224.

SAntos, A.; Dias, Á. Comportamentos lúdicos entre crianças do nordeste do Brasil: categorização de brincadeiras. Psicologia: teoria e pesquisa, Brasília: Instituto de Psicologia da Universidade de Brasília, v. 26, n. 4, p. 585-594, out./dez. 2010.

Serbin, L. Teachers, peers and play preferences: an environmental approach to sex typing in the preschool. In: Delamont, S. (Org.). Reading on interaction in classroom. Grã-Bretanha: Richard Clay LTD, 1984. p. 273-289.

Silva, P.; Botelho-Gomes, P.; Goellner, S. Educação física no sistema educativo português: um espaço de reafirmação da masculinidade hegemônica. Reviista Brasileira 
de Educação Física e Esporte, São Paulo: Universidade de São Paulo, v. 22, n. 3, p. 219-233, jun./set. 2008.

Silva, T. Documentos de identidade: uma introdução às teorias do currículo. 3. ed. Belo Horizonte: Autêntica, 2011.

Simões,A.; Cortez,J.; Conceição,P. Mulher e esporte de competição e de rendimento: as várias fases do social, do biológico e do psicológico. In: Simões, A.; Knijnik, J. O mundo psicossocial da mulher no esporte: comportamento, gênero e desempenho. 1. ed. São Paulo: Aleph, 2004. p. 131-152.

Souza, M.Transição de valores e a perspectiva sobre o "novo homem". In: (Org.). Desigualdades de gênero no Brasil: novas ideias e práticas antigas. 1. ed. Belo Horizonte: Argvmentvm, 2010. p. 239-265.

Torrão Filho, A. Uma questão de gênero: onde o masculino e o feminino se cruzam. Cadernos Pagu, Campinas: Núcleo de Estudos de Gênero, n. 24, p. 127-152, jan./jun. 2005.

Víctora, C.; Knauth, D.; Hassen, M. Metodologias qualitativa e quantitativa. In: .; _____ Pesquisa qualitativa em saúde: uma introdução ao tema. 1. ed.

Porto Alegre: Tomo, 2000. p. 33-44.

Thompson, M. Sex stereotyping and human development. Seek equity educationally in elementary school physical education. Urbana Champaign: University Illinois, 1981.

\section{SOBRE O AUTOR}

Marcos Vinicius Pereira Monteiro é doutorando em educação em ciências e saúde pela Universidade Federal do Rio de Janeiro (UFRJ). Professor do Colégio Pedro II (CPII).

E-mail: profmarcosvmonteiro@gmail.com

Recebido em 13 de junho de 2014 Aprovado em 16 de março de 2015 